\title{
A Study of Context and Figurative Language in Buchi Emecheta's "The Rape of Shavi”: A Pragmatic Approach
}

\author{
Datondji Cocou André \\ Department of English, Abomey-Calavi University, Abomey-Calavi, Republic of Benin
}

Email address:

datondjia@yahoo.fr

\section{To cite this article:}

Datondji Cocou André. A Study of Context and Figurative Language in Buchi Emecheta's "The Rape of Shavi”: A Pragmatic Approach. Communication and Linguistics Studies. Vol. 3, No. 1, 2017, pp. 5-14. doi: 10.11648/j.cls.20170301.12

Received: October 3, 2017; Accepted: October 31, 2017; Published: November 30, 2017

\begin{abstract}
This article is a pragmatic analysis of the figurative language used by the Nigerian writer Buchi Emecheta in her novel "The Rape of Shavi" published in 1983. It is an attempt of interpretation of the implied meaning she conveys to her readers through allusions, metaphors, similes and symbols. The analyzed data were collected through a selection of some important instances of figurative language during the proofreading of the novel. The interpretations were made with the integration of references and presuppositions relating to the author's sociocultural and educational background that constitutes the contextual makeup of the novel. The analysis of the figurative language instances reveals that more is being communicated than written and that the intended message can only be uncovered by reaching beyond the bare linguistic structure. I concluded that the novel is a multiple layer literary work that requires from the reader, the possession of a shared knowledge with the author in order to reach an efficient interpretation that discloses the very message that lies beyond the words.
\end{abstract}

Keywords: The Rape of Shavi, Buchi Emecheta, Pragmatics, Figurative Language, Sociocultural Context, Educational Background, Shared Knowledge

\section{Introduction}

This paper is an investigation into the figurative language used by Buchi Emecheta in her novel "The Rape of Shavi" in order to disclose the intended message contained therein through contextual interpretation. Basically, the meaning carried by language in a process of communication is semantically viewed on a denotative strand. On another level, when more is communicated than said or written, language is shifted up to the pragmatic meaning. To uncover the implied message, the listener or reader has to take into account pragmatic components such as deictic information, cooperative principle, implicature, presupposition, altogether with context. Be it linguistic or paralinguistic, context plays a paramount role when meaning depends less on dictionary meaning than on speech situation. The aim in carrying out this study is to highlight the figurative use of language as a means of conveying meaning in an artistic and aesthetic way in order to create images in the mind of the reader. The objective of this study is, hence, to select some instances of figurative language in the novel where the linguistic structure is at half way of the real message the writer intends to convey. Such instances will then be analysed on a pragmatic basis through an interpretation that matches both linguistic structure and contextual parameters in an attempt to be as close as possible to the author's presuppositions in a shared world of discourse.

While reading or listening to some pieces of language, one normally aims not only to understand what the words mean, but what the writer or speaker of those words intend to convey [39]. In fact, distinct words in the lexical neutral environment of a dictionary have their literal meaning that may change substantially once they are used in real social interactions. This characteristic of language offers both innumerable research perspectives as well as tremendous possibilities in the ways meaning can be loaded in words. Various scholars have undertaken the task of analysing language with the aim of describing how it is used by individual speakers / writers in specific instances to convey meaning in the most appropriate way. Words have power in the way they are used to build sentences [6]. Every act of communication implies some choices from interlocutors. The 
latters may decide to play on a denotative or connotative layer, depending on the conditions and the goal they want to achieve through language. Writers in various cases choose to use figurative language in their willingness to be more creative, artistic and aesthetic. The interest in using figurative language, Johansen [43] posits, is to prompt the reader's thirst to search beyond the bare words and to continue looking for more in the participative perspective of an active reader. The alternation between literal and figurative language is common and almost natural in human communication. As a matter of fact, as Halliday [21] contends, 'the internal organization of language is not arbitrary but embodies a positive reflection of the functions that language has evolved to serve in the life of social man'. Language use is a purposeful behaviour [14] and it depends on the writer to use it the way he/she considers most appropriate to achieve the intended communicative goal. Language is not a neutral instrument. It is a thousand ways biased [influenced] [6]. The denotation and connotation of a word or expression, as Norgaard [28] suggests, may vary according to the context in which it occurs. Indeed context is of critical importance while discussing the use of figurative language in literary works. When language is studied in use, context always comes first, directing the process of meaning construction from the very beginning [49]. The production of a literary fictional work brings the author to design a backdrop made up of the person, spatial and temporal deictic elements, references and inferences that work altogether in the communicative process in a specific context. Such a context is composed of the sociocultural aggregates of the writer on the one hand and of his/her personal experiences on the other. In this perspective, Verschueren [52] suggests a definition of context by describing it as any combination of ingredients of a communicative event, along any parameters of variability, with which linguistic choices are interadaptable, depending on interlocutors' orientation. The accurate identification of the intended meaning in such a complex linguistic and contextual environment depends largely on an efficient interpretation of the very close relation between the linguistic structure and surrounding contextual parameters. As a matter of fact, structure and context are not independent from each other, for one thing, every utterance becomes part of the context as soon as it has been produced [52]. The key point of the difference between the denotative meaning and connotative meaning loaded into a sequence of words lies in the variability and peculiarity of what context brings in. This corroborates Widdowson's [38] postulate cited in Song [51] that the achievement of pragmatic meaning is a matter of matching up the linguistic elements of the code with the schematic elements of the context. The conceptual oddity encountered in the attempt of literal interpretation of figurative constructs makes the importance of such schematic elements even more sensitive. Contextual influences on metaphorical interpretation for example have been noted before, but they have rarely received any systematic attention [39] and I read it as an additional motivation to the current study. Various authors acknowledge the role of 'contextual factors' in the recognition and interpretation of figurative language; some argue that they constrain the range of possible interpretations [16] [46], but none of them attempts to explicate this role of the context. Figurative language achieves its goal through the breaking of the limit of conventional meaning by the writer / speaker and the satisfactory decoding of the newly created propositional content by the reader / hearer. This work is undertaken along a theoretical background based on an insightful grasp of figurative language and some of the linguistic devices used.

\section{Theoretical Background}

This paper is grounded on linguistic pragmatics based on the important role of context in the interpretation of implied meaning that goes beyond semantic meaning. The limit between semantics and pragmatics is often blurred as language is scarcely ever used out of context. However, as Rudolph Carnap [8] cited in Morris [47] specifies, "if in an investigation, explicit reference is made to the speaker, or, to put it in more general terms, to the user of language, then we assign it to the field of pragmatics". This is the case in this paper in which the focus is set on the way Buchi Emecheta uses language to convey meaning in a special way in her novel. This theoretical framework provides scholarly approved definitions as well as illustrations relating to pragmatics and figurative language in context that are the underpinning theoretical concepts to the study.

\subsection{Pragmatics}

Pragmatics is the study of what speakers mean beyond the linguistic structure. It is the opposite of semantic meaning which is encoded in what is uttered. In the words of Leech [24], pragmatics is the study of meaning which is related to the speech functions. It is the study of the factors that govern our choice of language in social interaction and the effect of our choice on others [12]. In spite of the slight difference in the way scholars define pragmatics, the recognition of the existence of an implied, invisible, extralinguistic or intended meaning remains permanent. The uncovering of such a meaning that lies beyond the bare words makes appeal to pragmatics components such as the linguistic and the physical context, deictic information, reference, implicature, the cooperative principle and presuppositions as defined below.

i) The linguistic context, or co-text of a word is the set of words used in the same phrase, sentence or paragraph that influence the interpretation of meaning. It limits our range of possible interpretations. This is what Saeed [30] terms discourse as context.

ii) "The physical context is the relevant context in our mental representation of those aspects of what is physically out there that we use in arriving at an interpretation" [39]. As far as this aspect of context is concerned, Saeed [30] identifies knowledge as context and distinguishes background knowledge and mutual knowledge as essential components of context. The background, common-sense, 
encyclopedic, sociocultural or real-world knowledge is the knowledge a speaker might calculate others would have before, by virtue of membership in a community. The mutual knowledge is the background knowledge the speaker may think the hearer shares, but without certainty [30]

iii) Deixis is the part of language involved in locating what is talked about, relative to the speaker's point of view whether in space (here - there, this - that), time (now, then), discourse (former - latter), or social relation (I, you) [35].

iv) Reference is an act by which a speaker (or writer) uses language to enable a listener (or reader) to identify something. Inference, anaphora and Exophora are subparts of reference.

v) Implicature denotes either the act of meaning or implying one thing by saying something else, or the object of that act. Implicature can be part of sentence meaning or dependent on conversational context, and can be conventional or unconventional. Figures of speech provide familiar examples of implicature.

vi) Cooperative principle as described by the philosopher Paul Grice is a principle that represents the knowledge that verbal communication is an activity in which individuals work together to accomplish shared, mutually beneficial goals. The cooperative principle is supported by four maxims termed Grician maxims that are quantity, quality, relation and manner maxims [39].

vii) A presupposition is what a speaker (or writer) assumes is true or known by a listener (or reader). It is a prediction that is taken for granted, when a sentence is uttered or written, [35]. Information contained in a presupposition remain true with the constancy under negation test which consists in negating a sentence by focusing that specific information.

\subsection{Figurative Language}

There are two ways of using words and phrases: the literal and congruent way and the figurative and incongruent way [41]. Figurative language is a non-literal form of language that uses words deviating from their proper definitions in order to achieve a more complicated understanding or heightened effect, which makes it necessary to go beyond the bare-bones literal meanings [31]. Figurative language is often achieved by presenting words in order for them to be equated, compared, or associated with other normally unrelated words or meanings [53]. Figurative language is more easily understood by contrast with literal language that confers meaning to words, in the sense of the meaning they have by themselves, outside any figure of speech.

As defined in the Merriam Webster online dictionary [53], a figure of speech is a form of expression used to convey meaning or heighten effect often by comparing or identifying one thing with another that has a meaning or connotation familiar to the reader or listener, it is an intended deviation from ordinary usage [29]. Figures of speech allow the speaker or writer to mean a lot in fewer words than literal use of language. It is a peculiar expression of a sentiment different from the ordinary way. The use of figures of speech is a salient pattern in daily communications as it provides the necessary rhetorical devices to link abstract emotional or philosophical concepts with material objects, which makes it instrumental in creating powerful and dynamic communication. Figures of speech result in a more vivid scene by making meaning much iconic through an intensification of the emotional impact. The hearer / reader is then made an active participant while he/she skims through his/her sociocultural encyclopaedia for the denotative meaning of the figurative language. Some figures of speech are allusions, metaphor, simile, and symbolism.

\subsubsection{Allusions}

A literary work is by definition a work of fiction inspired by the realities of society. The use of literary devices in such works plays an important role, especially as they allow the author to make indirect reference to something not specifically identified, but intended to be recognized, in the form of allusions. An allusion is an indirect reference, by word or phrase, to a supposedly known fact but not explicitly mentioned. This goes along with the words of Abrams [1], who posits that an allusion is a passing reference, without explicit identification. The use of allusion presupposes knowledge of the fact, thing or person alluded to on the part of the reader or listener. An allusion is a mention of a word or phrase which may be regarded as the key-word of the utterance.

\subsubsection{Metaphors}

The word metaphor derives from the Greek metaphora, which breaks into two parts: meta ("over") and pherein ("to carry"). It is a creative use of language [4]. A metaphor serves to generate an image of reality by connecting apparently disparate objects' [36] in a way of iconizing the conveyed meaning. In the words of Bloor and Bloor [5], it is a more oblique realization of meaning as opposed to the straightforward one. In a metaphor, a word or expression that in literal usage denotes a specific kind of meaning is applied to a distinctly different kind of connotative meaning, without using any word that indicates a comparison. In rhetoric and other traditional approaches to figurative language, a metaphor is defined as a figure of speech, or trope, and is often seen as a kind of linguistic embellishment. A metaphor is made up of two elements that are the metaphorical term and the subject to which it is applied. Kazemian [22] and Leech [23] cited by Goatly [20] furthers the description of the metaphorical term, first by locating metaphor within pragmatics rather than semantics and secondly by identifying three elements in its comprehensive makeup:

i. the vehicle: the conventional referent of the unit, the object whose attributes are borrowed;

ii. the topic or tenor: the unconventional referent, the subject to which attributes are ascribed;

iii. the grounds: the similarities and/or analogies involved.

Another classification based on the main components - the tenor, the vehicle and the ground - identifies two main types of metaphors: direct and implied metaphors. The implied metaphor specifies the vehicle, but not the tenor, which has 
to be inferred from the context [45]. The characteristic feature of metaphors being that of meaning transfer from a conventional referent to an unconventional one, a direct metaphor is identified by the presence of both the tenor and the vehicle as in the sentence "life is a journey" wherein both the vehicle (journey) and the tenor (life) are clearly specified. On the opposite, in an implied metaphor, one of these components is not provided as in "your words fill and refresh my heart" in which the reader has to consider the context and decipher the vehicle that may be chilled water that goes along with the tenor - the words - on the ground of filling and refreshing.

\subsubsection{Simile}

A simile is a figure of speech that makes an explicit comparison, showing similarities between two dissimilar things. Unlike a metaphor, a simile draws resemblance with the use of connectives such as "like", "as", "than" or verbs such as "resemble" that exemplifie similarity. The phrasing of simile is termed as a rhetorical analogy, as it is a device used for comparison. Simile and metaphor are at times considered by some scholars as similar, as they are just slightly different at the surface level with the presence or not of connectives. However, these two tropes have one other major distinguishing feature which is that of the level of likeness. As McClanahan [27] puts it, simile is usually limited to likeness, whereas metaphor often implies a whole range of like qualities as shown in the following two examples: (i) Simile: My wife is like a twin sister, (ii) Metaphor: My wife is my twin sister.

\subsubsection{Symbol and Symbolism}

A symbol is a visible sign - an object or action - that points to a world of meaning beyond itself [27]. It is a literary device that contains several layers of meaning, the literal and the symbolic one often concealed at first sight that encapsulates several other aspects, concepts or traits than those that are visible. Whereas metaphor and simile are built on the comparison between a tenor and a vehicle, the symbol provides information on the vehicle only. Due to its important part in the meaning process of civilisations worldwide, various other knowledgeable sources provide definitions and insights about symbols and symbolism. The Merriam Webster online dictionary [53] defines symbolism through its derivation from the Greek word "symballein meaning "to throw together" and Latin "symbolum" meaning sign. The Longman Dictionary of the English Language defines symbol as "something that stands for or suggests something else by reason of relationship, association, convention or accidental resemblance. These definitions suggest a paring both at the level of the existence of the sign and in its meaning system. Symbolism thus appears to be the art or the practice of representing things by symbols, or giving things a symbolic meaning. It is a literary or an artistic mode of expression of the symbolists. In the phrase "to climb up the ladder of success" for example, the word "ladder" is used as a symbol of a movement of ascension or promotion. This example displays another distinctive feature of symbolism which is the use of a concrete thing as the symbol at the surface layer and the projection to an abstraction representing the deep layer component that is the core content of the message. When symbolism is used, it is then possible to derive meaning from these two levels.

All these aspects that have been covered so far have been used in various ways in the novel under study, which I attempt to analyse in the following section along the specified methodology.

\section{Methodology}

This article is written after several proof readings of the novel during which I noticed that the author used language on two distinctive layers: the denotative and the connotative. This observation was followed by my willingness to emphasise my research on the instances in this literary work in which meaning was rather to be decoded on a pragmatic track, beyond the bare linguistic structures. The next step in my research method was to select the cases of figurative language use with a focus on allusions, metaphors, simile and symbolism on the basis of the scholarly definitions provided in the theoretical background. The emphasis on pragmatic meaning has been specified through the reference to the intended meaning conveyed by the writer with an indication of the major role of contextual parameters including presuppositions, shared knowledge, and information relevance assessment with the Gricean cooperative principle.

The analysis of the selected data started from an attempt of interpretation of the general figurative language backdrop underpinning the linguistic of the author. Some important aspects of the author's biography with some features of the social and political state of her native country have been instrumental at this regard. I proceeded with the intended meaning decoding scrutiny through the previously identified figurative language devices.

The selected allusive passages have been classified into religious and historical ones according to the extralinguistic elements provided from outside the novel for their interpretation. Metaphors have been categorised into direct and implied ones, with a specification of their vehicles, topics and grounds. The analysis of symbolic instances closed the meaning decoding series. The discussion of the results highlights the linguistic choices of the author with an identification of its probable origins together with an appraisal of the readership's expected attitude for a full grasp of the conveyed message.

\section{Results and Discussion}

\subsection{Pragmatic Analysis in "The Rape of Shavi"}

\subsubsection{Analysis of Context in the Novel}

When language is analysed on a pragmatic layer, it becomes necessary to consider parameters of the non- 
linguistic context that can provide hints to an efficient interpretation. Features such as the sociocultural and political conditions and even some private aspects relating to the author thus become important. Buchi Emecheta was born on July 21, 1944, when Nigeria was still a British colony. She lost her parents very young and attended a missionary school till she left Nigeria to join her husband in England where the impact of the cultural clash was increased by the hardship in her marital life as she painstakingly portrays in her other novel "Second Class Citizen". During her childhood, Buchi Emecheta used to attend moments of storytelling by her aunt whom she affectively named "Big Mother". All these experiences that paved her life set up the bulk of her encyclopaedic knowledge that represents a great deal of her source of inspiration. The pairing between these bits of daily experiences and the way she uses language in "The Rape of Shavi" raises various interpretations with the presence of the British coloniser, the storytelling moments and the attendance of the missionary school as backdrop.

i) The presence of colonial dominion in Nigeria: this is reflected in the novel as the rape of African culture and social organization. This contextual aspect shows up in the novel through some comparisons between Africans paired with slavery and intellectual incapacity on the one hand and the Europeans assimilated with royal blood and particular intellectual capacities on the other. This is a confirmation of Bedana et al.'s [40] postulate that Emecheta's novels draw heavily upon Nigerian beliefs and post-colonial culture and often portray the clash that occurs when the modern world encroaches upon indigenous African value systems.

ii) The storytelling moments: storytelling in Africa are particular instances of cultural transmission when the elderly generation transmits ways of social life to the younger one through purposely plotted stories with specific ways of using language. These are instances that take place among people sharing the same language and the same background history, which facilitates the deciphering of figurative language through shared knowledge. This aspect too which is part and parcel of Buchi Emecheta's childhood is one of the features that tend to label this novel as one written for insiders. In the novel, the dance of the Queen Mother Shoshovi described as "beautiful and graceful and one of which every movement conveyed a meaning, lost to outsiders" is an illustration of this sense of community membership. The author thus presupposes that a common discourse ground is available on the reader's part who can reach the conveyed message through inference.

iii) The attendance of the missionary school: this part of the writer's life explains her recurrent allusions to religious practices, characters and places. In addition to Buchi Emecheta's individual religious experience, her Igbo cultural background is recognized for granting a high consideration to everything that is linked to religion. Emmanuel Oknonkwo cited by Bedana et al. [40] is rather straight to point out that the Igbo are a religious people.

\subsubsection{Analysis of Figurative Language in the Novel}

\section{A General Appraisal of Some Figurative Language Instances in the Novel}

The use of figurative language in "The Rape of Shavi" starts from the cover with the title of the novel. The author manages in such a way to provide an intelligible content to her language on the denotative level while simultaneously leading the reader, through the plot development, to discover the connotative meaning which eventually appears to be the core of her message. These are a few illustrations of such instances through the title of the novel and the nickname of the king.

i) The title of the novel: "The Rape of Shavi"

a) Denotative meaning: a rape is an unlawful sexual activity and usually sexual intercourse carried out forcibly or under threat of injury, against the will usually of a female or with a person who is beneath a certain age or incapable of valid consent.

b) Denotative meaning identification: In the novel, one of the Albinos, Ronje, raped Ayoko who thereby lost her brilliant future of becoming the wife of Assogba, the king-tobe. The identification of Shavi as the victim of the rape in the title of the novel indicates the necessity of an interpretation for a full decoding of the message that is being communicated.

c) Connotative meaning interpretation: Shavi is the halfbrother of king Kokuma. He is the one who led his people from the land of slavery to the land of freedom. The new land they joined was named Shavi, after his name, which means that the rape of Shavi cannot be taken on the denotative layer. It is rather to be understood as the crash-landing of the albinos in Shavi and the subsequent total disruption they caused in the Shavian culture. This connotative interpretation is confirmed by the Queen Mother Shoshovi who declares: "Shavi is the Mother of us all. She has been raped once, and we must never allow her to be raped again." (p. 178)

ii) The nickname of the king: "The Slow One, Slow thinking and easy going":

a) Denotative meaning: the word "slow" as used here is an adjective meaning not quick, not conducive to speed, taking a relatively long time to do a thing.

b) Denotative meaning identification: in the novel, king Patayon truly exemplifies slowness in his royal behaviours, in his ways of managing matters in the kingdom. He hates approaching any topic with haste, usually indulging in long communicative silence during his meetings, which is but a superficial part of the message.

c) Connotative / figurative meaning interpretation: Beyond the superficial and common message conveyed through the phrases "Slow One", "Slow thinking" and "easy going" which goes along with shyness and dullness in decision making, Emecheta is pointing out the lack of diligence from African leaders in the management of public affairs, which seriously impairs the social conditions of the citizens. This inferred meaning is justified by the following interrogation of Assogba at the end: "And why should our ruler be called "the 
Slow One"? Are these flattering titles? (p. 161), followed by the negative replies of the young men.

This simultaneous denotative and connotative use of language by the author allows her to address social matters with a style that remains accessible to a large readership and invites the latter to continuously dig beyond the surface layer in the search of the real communicative goal. While this choice from the author exemplifies her willingness to use language in this pragmatic way, it also provides an impetus that entices the reader to the literary work.

\section{Analysis of Specific Figurative Language Devices in the Novel}

\section{A- The Use of Allusions}

As defined earlier, an allusion is an indirect reference made to something or a reality without mentioning it but with the supposition from the speaker/writer that the hearer/reader will decipher it. Allusions in a literary work bring back to the communication scene, some shared or supposedly known knowledge about the fact or situation that is being alluded to. More than a literary input aimed at improving the value of her work, the use of allusions by Emecheta appears as a readiness and willingness to share her personal experiences with the readership. This comes as a confirmation of the words of Bedana et al. [39] who writes that many of Buchi Emecheta's works are autobiographical that would be best described as "stories of the world". By way of illustration, various allusions instances have been selected from the novel and paired with their correspondence to various aspects of Buchi's personal experiences.

i) Religious allusions: they are predominant in the novel and illustrate the importance of religion to the author and serve as a proof of the assumption that the Igbo are a religious people [40].

a) "For a hundred days, they trekked, stopping only to rest when the sun was too high" (p. 23): this is an allusion to the trek in the desert by Israel as mentioned in the Book of the Exodus in the Bible. The hardships endured by the people of Shavi is in parallel to that of the Israeli people on their long forty years trek from the land of slavery, Egypt, to the land of freedom and abundance, Canaan.

b) "One of the men that came was a clergyman, wearing his ecclesiastical air, ready to pronounce the last rites" ( $p$. 140): this is an allusion to the sacrament applied by Roman Catholic priests to people who are particularly sick and showing signs of imminent death.

c) ".....it was like the conversion of Saul of Tarsus" ..... (p. 90): This is an allusion to Saul of Tarsus in the Acts of Apostles in the Bible, who used to persecute Christian believers because of their faith. He was eventually converted to the same faith after an encounter, as the Bible indicates, with the Lord Jesus on the road of Damascus.

d) The discovery of the Shavi stones by Flip (p. 57) is an allusion to the wealth found in the Promised Land by the Israeli in Canaan.

e) "I keep telling people that there is a big Man or Woman up there, who is watching everything with amusement. He just wouldn't let us tiny creatures blow up this wonderful earth He/She has created". (p. 143): this is an allusion to the Almighty God as described in the Holy Bible. Christians consider Him as the One managing the whole past, present and future affairs of the earth in the spiritual realm.

f) "Sometimes they say $\mathrm{He}$ is one, sometimes they say $\mathrm{He}$ is three" (p. 163): this is an allusion to the belief by Christians that God exists in three persons as God the Father, God the Son and God the Spirit.

g) "Some of them go to big buildings on special days and worship some person they say is the Son of the Almighty God" (p. 163): this is an allusion to Sunday as the worship day of Christians when they pray and worship the glory of Jesus Christ, the Son of God, as the Christian Holy Book, the Bible posits.

ii) Historical allusions

a) "A prince indeed, so what am I, Maggie Thatcher", the officer bayed, laughing." (p. 142): this is an allusion to Margaret Hilda Thatcher, Baroness Thatcher, the former British stateswoman who was Prime Minister of the United Kingdom from 1979 to 1990 and leader of the Conservative Party from 1975 to 1990 .

b) They thought that they had escaped from a nuclear holocaust (p. 90): this is a historical allusion to the Holocaust, also referred to as the Shoah that was a genocide in which some six million European Jews were killed by Adolf Hitler's Nazi Germany, and the World War II collaborators with the Nazis.

\section{B-Analysis of Metaphors in the Novel}

The author's choice to give her audience the opportunity to read beyond the literal and bare words also shows up through the use of metaphorical language. This creates in the mind of the reader, the images of the comparison between unrelated elements inside and outside the novel. It is worth mentioning that metaphors move a step further than similes in the sense that both the topic and the vehicle are attributed the same identity, not only on the ground of resemblance, but straight interchangeability. This unconventional pairing creates a twin image that puts the emphasis on the way the author's conveys messages. The amazement impact thus triggered on the reader through the aesthetic use of language and the queries thereby prompted are the actual sources of the iconic screens that show up in his/her mind. In "The Rape of Shavi", Buchi Emecheta uses two types of metaphors as far the indication of the topic and the vehicle is concerned. There are direct metaphors in which the topic and the vehicle are clearly identified and implied metaphors in which only the topic is stated and the vehicle implied. Table 1 presents a few examples of direct metaphors with an identification of the vehicle, the topic and the ground. Table 2 presents some implied metaphors with an attempt of interpretation of the corresponding vehicles and grounds. 
Table 1. Direct metaphors.

\begin{tabular}{lll}
\hline Metaphorical expressions / sentences & Vehicle & Topic \\
\hline Shame kills faster than disease & disease & shame \\
....and anger had twisted his thin mouth into the shape of a desert snail & desert snail & anger \\
$\begin{array}{l}\text { Ronje is an animal, for what human would destroy a beautiful person like you } \\
\text { "Modesty is a lovely robe" }\end{array}$ & animal & Ronje \\
The heat had now become a burden & burden & modesty \\
\hline
\end{tabular}

Source: myself

Table 2. Implied metaphors.

\begin{tabular}{|c|c|c|c|}
\hline Metaphorical expressions / sentences & Implied topic & Vehicle & Ground \\
\hline As usual, there was a long trembling silence & Human body & silence & trembling \\
\hline The silence that reigned after Assogba's footfall had died away & King & silence & Reigning /having control over all \\
\hline We have until now been swallowing their insult & some edible liquid & insult & swallowing \\
\hline ......his anger rules him & king & anger & ruling \\
\hline Sarcasm was written all over Ista's face & letters & sarcasm & written form \\
\hline They carry weapons of death in their speech & gun & speech & weapon carrying \\
\hline .....and don't see why we should go on working in this biting wind & snake & wind & biting \\
\hline Normally, after a weighty comment like this one.... & burden & comment & heaviness / particular importance \\
\hline The strong smell of rotting flesh hit them & strong person & smell & strength \\
\hline The strong smell of rotting flesh hit them & lash & smell & hitting \\
\hline ......that women are the softness on which our men recline & Soft sitting material & women & softness \\
\hline
\end{tabular}

\section{C-The Study of Symbolism in the Novel}

Before its use in literary works, symbolism used to be an integral part of communication devices whereby a visible or audible sign overtly manifested in the form of a verbal or iconic expression could convey a message. This message remained intelligible to a limited number of people, depending on their shared information that represent the keys to the interpretation. Symbolism thus gives the speaker or the writer, the possibility not only to use language in a figurative way, but also to share message in an exclusive way. This willingness of Buchi Emecheta is revealed when she aesthetically describes the dancing performance of the Queen mother as "a beautiful, graceful dance, of which every movement conveyed a meaning, lost to outsiders." This artistic way of using language through symbolism goes along with the words of Datondji [41] who posits that in the case of lexical deviation, various meaning interpretation processes may arise at the underlying level, depending on the experience of each reader. As a confirmation to this meaning deriving potential, Shibatani and Bynon [32] contend that cognition is achieved in the individual speech act when the speaker uses the forms of his or her language creatively in context-related utterance. In other words, the relationship between form and meaning is not only language-specific but also sufficiently elastic for new cognitive acts to be created and communicated.

In "The Rape of Shavi", the author uses symbolism in various instances to communicate with her readership in a way that requires social, historical and political insight of the context for full intelligibility to be achieved. The main character in this novel, Shavi, is symbolic at various regards. First of all, Shavi's mother is a woman from Ogbe Asaba, a community that was under the domination of King Kokuma who is the father of Shavi. The following meaning deriving interpretations may be suggested:

i) King Kokuma symbolises the colonisers who, in spite of the master-slave relationship they have with colonised African countries, fell in love with some of their women and had children from them.

ii) Shavi's mother is symbolic of those African women who had the so called honour to the "grace" of their masters' love and to bear children from them.

iii) Shavi is symbolic of the fruit of the encounter between the master and the slave and he bears the marks of this social contrast in his everyday life. The presence of royal blood in Shavi is the expression of that social gap. The refusal of the king to have it overtly known that Shavi is a prince is the expression of the shame of the "downgrading" love encounter.

At another level, Buchi Emecheta skilfully inserts in her novel, the request for freedom from King Kokuma's dominion. The author gives account of the king's interpretation and reaction as follows: "It didn't take the King long to realise that the brain behind the scheme was that of his half-brother, Shavi, the only man capable of thinking of freedom in Ogbe Asaba. No slave or any one born from slave parents would have done so. The King diplomatically agreed with the delegation (pp. 20-21)" This raises various symbolic instances that may be interpreted as follows:

The assumption that Shavi is the only man capable of thinking of freedom is symbolic of the false belief from colonisers that Africans are born with minor intellectual capacities.

The diplomatic agreement of the king to the delegation of Ogbe Asaba is symbolic of the fake independence granted by colonisers to most African countries who are still under economic and political dominion from their former so called mother countries. 


\subsection{Discussion of the Findings}

The previous analyses and interpretations carried out in this study confirm the relevance of the pragmatic background to this research work. The message communicated by the author can in fact be really decoded only when some extralinguistic contextual element are integrated. The novel is deeply rooted in a specific sociocultural context that provides the necessary hints for its understanding. Buchi Emecheta used allusions, direct and implied metaphors, similes and symbols to make the reader share part of her own encyclopaedia. In various instances, the linguistic context does not meet the quantity and relevance principles as indicated by Grice especially in the cases of allusions and implied metaphors. In fact, the way she uses language with these supportive devices requires from the reader the possession of a shared discourse ground in order to make the author's presuppositions work. Besides the linguistic context provided by the text of the novel, this discourse ground is composed of the sociocultural environment, as well as the biographical parameters of the author. The space and time deictic terms used by the author locate the geographical environment of the novel in a place in sub-Saharan Africa and in England. This brings an essential feed-in to the contextual factors for interpretative purposes. Reading this novel and getting a thorough grasp of the whole message therein communicated beyond the bare pages thus requires from the reader a well provided and cross cultural background like the author herself. Indeed, as Fishburn [18] puts it, "what we see in a text is what our ideology has equipped us to see".

Valuable enough to mention too is the place of figurative language in general and of symbolism in particular in African verbal communication in tales most specifically. The audience on such occasions is often composed of the close family, clan or community members whom the speaker assumes to possess the necessary shared knowledge. Besides this specifically communicative goal, the use of symbolism is better appreciated when some sensitive issues are to be evoked. As Goffman [43] states, symbols help people communicate and share their frames of thoughts because the frameworks of a particular social group constitute a central element of its culture and requires a mode of communication. Ashkanasy et al. [50] share the same view by pointing out that symbols reflect underlying aspects of culture as they elicit internalized norms of behaviour, linking members' emotional responses and interpretations. They frame experience, allowing community members to communicate about vague, controversial, or uncomfortable issues. Symbols thus represent a complex corpus of social makeup designed to convey meaning in specific contexts that are determined in a dynamic perspective by the audience, the setting and the communicative goal.

Analysing Emecheta's novels on this ground of cross cultural shared knowledge necessity, Fishburn [18] writes "I take it as given, therefore, that when we [Europeans] are faced with the problem of reading an African or any other text alien to our Western experience, we must recognize that our ability to understand will be impeded (to one degree or another) by fundamental differences that separate the two cultures". This assertion corroborates the necessity of the possession of a shared knowledge. While it may be interpreted in a way as a limit of intelligibility of the author's message to such alien readers, it should rather be considered, to my mind, as an impetus to such readers to be active and inquisitive enough to seek beyond the bare words and discover the real message. In this regard, Fishburn [18] proceeds and mentions that because of these sociocultural and individual encyclopaedic dissimilarities, the reader concentrates more on what may be called moments of misunderstanding, wherein the passages that puzzle, irritate, or alienate are isolated ...... for these are the moments when true learning occur.

\section{Conclusion}

This article has dealt with the interpretation of pragmatic meaning in the novel "The Rape of Shavi" written by the Nigerian female writer Buchi Emecheta. Context as approached in this work is the whole set of the sociocultural and educational environment that compose the encyclopaedia of the writer. The social background of the author, from her childhood and school years in Nigeria on the one hand and her experience in London on the other, have greatly contributed in the figurative language expressed through religious and historical allusions, direct and implied metaphors, similes and symbols. This partly subjective component of the novel appeals from the reader, the possession of some specific shared knowledge in order to achieve an optimal intelligibility of what is being communicated. The ability of the author to seek beyond the superficial is also present in the way she skilfully uses language in a pragmatic way that continually invites the reader to play an active part in the deciphering of her message. In spite of the pervasive presence of the author's cross-cultural biography in the novel, the skilful use of figurative language ends up in gaining the attention and interest of the average reader. Imagery eventually engages readers in the plot by making them experience joy, excitement and show concern.

\section{References}

[1] Abrams, M. H. (1999). A glossary of literary terms (seventh edition). United States of America: Cornel University

[2] Abrams, M. H. and Harpham, G. G. (2012). A glossary of Literary Terms (tenth edition). United States of America: Wadsworth Cengage Learning

[3] Aitchison, J. (2003). Linguistics. England: Hodder Education

[4] Black, E. (2006) Pragmatic Stylistics. London: Edinburgh University Press

[5] Bloor, T. \& Bloor, M. (2004). The Functional Analysis of English: A Hallidayan Approach, $\left(2^{\text {nd }}\right.$ Edition) United States of America: Arnold 
[6] Bolinger, D. (2014) Language - The Loaded Weapon: The use and abuse of language today. London and New York: Routledge

[7] Buchi, E. (1983). The Rape of Shavi (First Edition). Great Britain: William Collins Sons \& Co. Ltd.

[8] Carnap, R. (1942). Introduction to Semantics. United States of America: Harvard University Press

[9] Carter, R. (2004). Language and Creativity. London: Routledge

[10] Cooper, D. (1986). Metaphor. Oxford: Blackwell

[11] Croft, W., and Cruse A. (2004). Cognitive linguistics. Cambridge: Cambridge University Press

[12] Crystal, D. (2004), The Cambridge Encyclopedia of the English Language. Cambridge: Cambridge University Press

[13] Eco, U. (1984). Semiotics and the Philosophy of Language. Basingstoke: Macmillan

[14] Eggins, S. (2004) An Introduction to Systemic Functional Linguistics (Second Edition). London and New York: Continuum International Publishing Group

[15] Fandel, J. (2006). Metaphors, Similes, and Other Word Pictures. United States of America / Minnesota: The Creative Company

[16] Fogelin, R. J. (1988) Figuratively Speaking. New Haven: Yale University Press

[17] Fontaine, L. (2013). Analysing English Grammar: A Systemic Functional Introduction. Cambridge: Cambridge University Press

[18] Fishburn, K. (1995). Reading Buchi Emecheta: Cross Cultural Conversations. United States of America: Greenwood Publishing Group

[19] Glenn, C. (2012). The Harbrace Guide to Writing. Boston: Wadsworth

[20] Goatly, A. (1998). The language of metaphors. London: Routledge

[21] Halliday, M. A. K. (1978). Language as social semiotic. The Social Interpretation of Language and Meaning. London: Edward Arnold

[22] Kazemian, B. (2014). Hallidayan ideational grammatical metaphor in specialized texts. Germany: Lap Lambert Academic Publishing

[23] Leech, G. N. (1969), Towards a Semantic Description of English. London: Longman

[24] Leech, G. N. (1983). Principles of pragmatics. London: Longman

[25] Leezenberg, M. (2001). Contexts of Metaphor. United Kingdom: Elsevier Science Ltd.

[26] Lennon, P. (2004). Allusions in the Press: An Applied Linguistic Study. Berlin and New York: Mouton de Gruyter

[27] McClanahan, R. (2014). Word Painting: A Guide to Writing More Descriptively. United States of America: Writers' Digest Books

[28] Norgaard, N. et al. (2010). Key Terms in Stylistics. New York: Continuum International Publishing Group
[29] Quinn, A. (1982). Figures of Speech: Sixty ways to Turn a Phrase. United States of America: Peregrine Smith Book

[30] Saeed, J. I. (2007), Semantics, (3rd edition), Oxford: Blackwell Publishing

[31] Sam, G. (2001). Understanding Figurative Language: from Metaphors to Idioms. Oxford: Oxford University Press

[32] Shibatani, M and T. Bynon (eds). (1995b). Approaches to language typology: a Conceptus: Oxford: Oxford University press

[33] Sperber, D. and D. Wilson (1995). Relevance: Communication and Cognition, Oxford: Blackwell

[34] Sunderland, J. (2006). Language and Gender: An Advanced Resource Book. London and New York: Routledge

[35] Traugott, E. C. \& Pratt, M. L. (1980). Linguistics for Students of Literature. London and New York: Harcourt Brace Jovanovich

[36] Tunca, D. (2014). Stylistic Approaches to Nigerian Fiction. New York: Palgrave Macmillan

[37] Waugh, P. (1984). Metafiction. London: Methuen

[38] Widdowson, H. G. (2000). Linguistics. Shanghai: Shanghai Foreign Language Education Press

[39] Yule, G. (2010). The Study of Language (fourth edition). Cambridge: Cambridge University Press

[40] Bedana, L. et al. (2016). "Impact of Christianity on African Women. In Buchi Emecheta's Novels. Preprints (doi: 10.20944/preprints201607.0082. v1)

[41] Charteris-Black, J. (2003). "A contrastive cognitive perspective on Malay and English figurative language" In Jaszczolt K. M. and Turner, Meaning through Language Contrast. Volume 2 Amsterdam / Philadelphia: John Benjamins Publishing. (pp. 142-157)

[42] Datondji, C. A. (2014). A Study of the syntactic structures of new trade names in five francophone West African capital cities: a sociolinguistic perspective. Unpublished Doctoral thesis defended at the Université d'Abomey-Calavi, Benin

[43] Goffman, E. (1974). Frame analysis: An essay on the organization of experience. New York: Harper and Row

[44] Johansen, J. D. (2003). "Iconizing literature” In Müller, W. G. and Fisher, O. (Eds) From Sign to Signing Iconicity in language and literature. Amsterdam/Philadelphia: John Benjamins Publishing Company (379-410)

[45] Kruntz, J. K. (2008). "Growling dogs and Thirsty deer: uses of animal Imagery in Psalmic rhetoric". In Foster, R. L. and Howard, D. M. Jr. (Eds) My Words are Lovely: Studies in the Rhetoric of the Psalms. New York and London: T\&T Clark. Pp. 46-62

[46] MacCormac, R. (1985) "Suburban syntax" In Architectural Review (October 1985 Edition). United Kingdom: Metropolis

[47] Morris, W. C. (1955) "Value Scales and Dimensions." In Journal of Abnormal and Social Psychology (51 $1^{\text {th }}$ Edition) USA: American Association of Psychology. Pp. 523-535

[48] Okonkwo E. (2003) "Marriage in the Christian and Igbo Traditional Context: Towards an Inculturation”. Frankfurt/M: Peter Lang 
[49] Porto Requejo, M. (2007). "The Role of Context in Word Meaning Construction: A Case Study". International Journal of English Studies, Vol. 7, pp. 169-173

[50] Rafeli, A. \& Worline, M. (2000). "Symbols in organizational culture". In Ashkanasy, N. M., Wilderom, C. P. M., and Peterson, M. F (Eds). Handbook of organisational culture and climate. United States of America: Sage Publications, Inc. (pp 71-84)

[51] Song, L. (2010). "The Role of Context in Discourse Analysis." In Journal of Language Teaching and Research, Vol. 1, No. 6, pp. 876-879, November. Finland: Academy Publisher doi:10.4304/jltr.1.6.876-879
[52] Verschueren, J. (2008) "Context and Structure in a Theory of Pragmatics.” In Studies in Pragmatics Vol 10, pp. 14 - 24, Belgium: University of Antwerp

[53] https://www.merriam-webster.com/dictionary retrieved on September $11^{\text {th }}, 2017$

[54] https://en.wikibooks.org/wiki/Linguistics/Pragmatics retrieved on September $20^{\text {th }}, 2017$

[55] https://fr.slideshare.net/mehwishnazar77/pragmaticspresentation-36657885 retrieved on September $30^{\text {th }}, 2017$ 